\title{
Open Maximal Mucosa-Sparing Functional Total Laryngectomy
}

\author{
Pavel Dulguerovi ${ }^{1 *}$, Naif H. Alotaibi', Stephanie Lambert ${ }^{1}$, Nicolas Dulguerov ${ }^{1}$ \\ and Minerva Becker ${ }^{2}$
}

${ }^{1}$ Department of Oto-Rhino-Laryngology - Head and Neck Surgery, Geneva University Hospitals (HUG), Geneva, Switzerland, ${ }^{2}$ Department of Imaging and Medical Information Sciences, Geneva University Hospitals (HUG), Geneva, Switzerland

Background: Total laryngectomy after (chemo)radiotherapy is associated with a high incidence of fistula and therefore flaps are advocated. The description of a transoral robotic total laryngectomy prompted us to develop similar minimally invasive open approaches for functional total laryngectomy.

Methods: A retrospective study of consecutive unselected patients with a dysfunctional larynx after (chemo)radiation that underwent open maximal mucosal-sparing functional total laryngectomy (MMSTL) between 2014 and 2016 is presented. The surgical technique is described, and the complications and functional outcome are reviewed.

OPEN ACCESS

Edited by: Umamaheswar Duvvuri, University of Pittsburgh, United States

Reviewed by: Rajagopalan Raman, University of Malaya, Malaysia Narayan Jayashankar, Nanavati Superspeciality Hospital, India

*Correspondence: Pavel Dulguerov pdghns@outlook.com

Specialty section: This article was submitted to Otorhinolaryngology Head and Neck Surgery, a section of the journal

Frontiers in Surgery

Received: 26 April 2017 Accepted: 27 September 2017 Published: 12 October 2017

Citation:

Dulguerov P, Alotaibi NH, Lambert S, Dulguerov N and Becker M (2017) Open Maximal Mucosa-Sparing Functional Total Laryngectomy. Front. Surg. 4:60. doi: 10.3389/fsurg.2017.00060
Results: The cohorts included 10 patients who underwent open MMSTL. No pedicled flap was used. Only one postoperative fistula was noted (10\%). All patients resumed oral diet and experienced a functional tracheo-esophageal voice.

Conclusion: MMSTL could be used to perform functional total laryngectomy without a robot and with minimal incidence of complications.

Keywords: total laryngectomy, aspiration, swallowing, surgical technique, robotics, complications, flap reconstruction

\section{INTRODUCTION}

In a landmark article, Lawson et al. (1) described in 2013 a new surgical technique for total laryngectomy: the transoral robotic laryngectomy. The technique involved preparing the supraglottic larynx transorally with pre-epiglottic and retroarytenoid mucosal incisions followed by a progressive dissection around the laryngeal cartilages in an inferior direction. A cervical incision is necessary for the creation of the tracheostomy but the larynx is delivered transorally. The exact amount of transoral vs. transcervical dissection was not specified, but heavy emphasis is placed on the use of endoscopic robotic dissection.

This article is essentially a technical note without clinical details such as the exact indications for the procedure, the duration of the procedure, the number of patients, or the complications associated with procedure.

This article inspired us to modify traditional laryngectomy techniques in cases of a dysfunctional larynx after (chemo)radiation, the so-called functional laryngectomy. The technique retains the main advantages of the transoral robotic laryngectomy: (1) minimal neck incisions, (2) maximal mucosa sparing, (3) minimal pharyngotomy defect, (4) minimal lateral dissection toward the carotid sheath, (5) horizontal closure, and (6) preservation of prelaryngeal muscles, allowing minimizing the risk of fistula. 


\section{MATERIALS AND METHODS}

\section{Surgical Technique}

The procedure is performed through a $5-$ to $6-\mathrm{cm}$ horizontal neck incision, usually by $2-\mathrm{cm}$ lateral extensions of the tracheostomy incision (Figure 1). Since no tracheal sacrifice is necessary, the tracheostomy is planed as high as the first or second tracheal ring. If a previous tracheostomy is placed it is modified as necessary to create an adequate stoma.

The prelaryngeal musculature is divided in the midline from the hyoid bone to tracheostomy site and the anterior aspect the thyroid and cricoid cartilage dissected. The dissection at the posterolateral aspect of thyroid cartilage is minimal at this point (Figure 2). The attachments of the thyrohyoid muscle are severed at the upper border of the thyroid cartilage. If the upper cornu of thyroid cartilage is prominent it can be sectioned along the natural line of the upper border of the thyroid cartilage and left in place. The tracheostomy is created.

After dissection in the pre-epiglottic fat, the epiglottis is felt, grasped, and pulled in an anterior direction. Mucosal incisions are performed following the epiglottic edge, 1-2 $\mathrm{mm}$ on the laryngeal side of epiglottis. The larynx in brought in full view by an anterior traction (Figure 3).

An incision of the mucosa on the upper border of the posterior cricoid ring, just behind the arytenoids is performed (Figure 4). The dissection proceeds inferiorly, against the posterior aspect of the cricoid cartilage, freeing retrocricoid and esophageal mucosa from the cricoid cartilage and posterior tracheal wall. At some point, the dissection is taken laterally through the paraglottic space to the inner aspect of the thyroid cartilage, the mucosa of the pyriform sinuses is dissected from the thyroid cartilage from the inside out, and the attachments of the constrictor muscles to the lateral border of the thyroid cartilage severed.

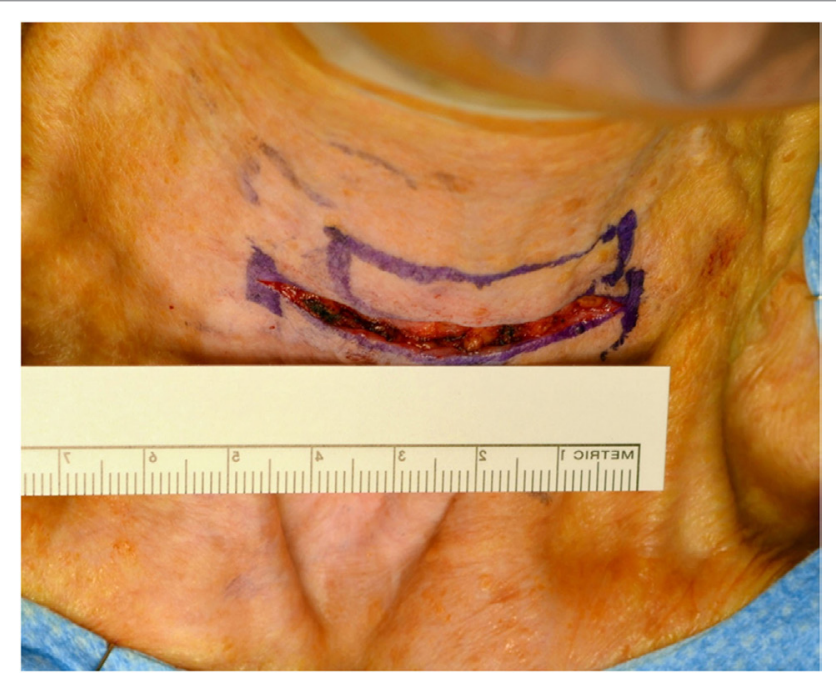

FIGURE 1 | Neck incision for maximal mucosa sparing functional total laryngectomy.
The esophageal musculature is minimally disturbed since the dissection proceeds along the cricoid cartilage and posterior tracheal wall under direct vision. The larynx is than delivered and is basically made up of skeletonized laryngeal cartilages, leaving a pharyngeal defect of about 4-5 cm (Figure 5).

A tracheal esophageal puncture is performed, and the prosthesis is placed primarily. The pharyngotomy is closed horizontally, without any undue tension (Figure 6). The prelaryngeal muscles are sutured at the midline, and the tracheostomy and neck incisions closed.

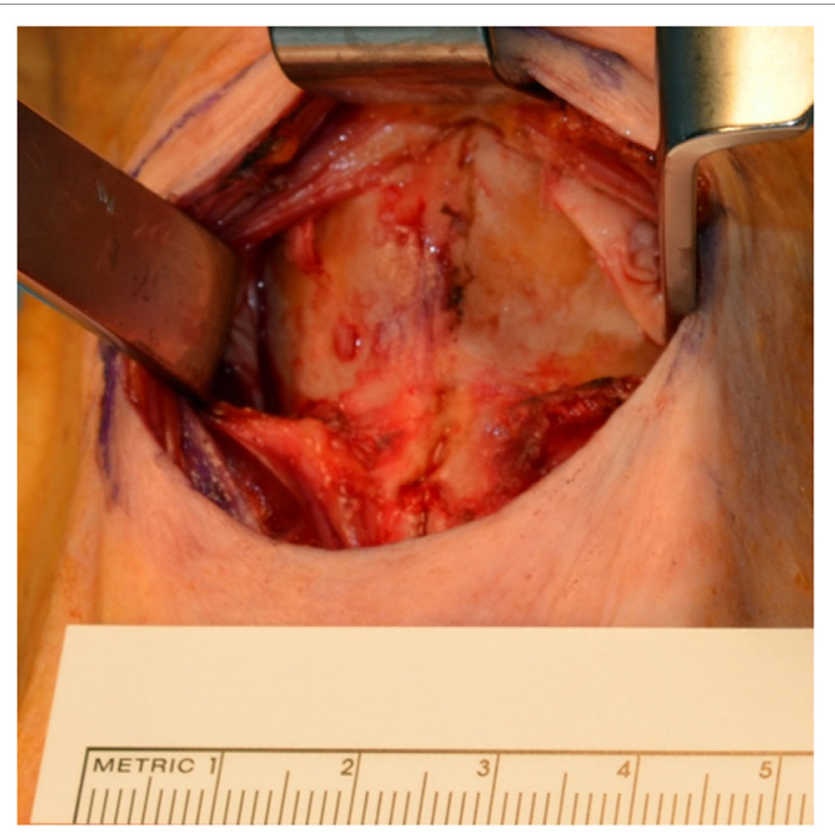

FIGURE 2 | Dissection of anterior aspect of thyroid and cricoid cartilages.

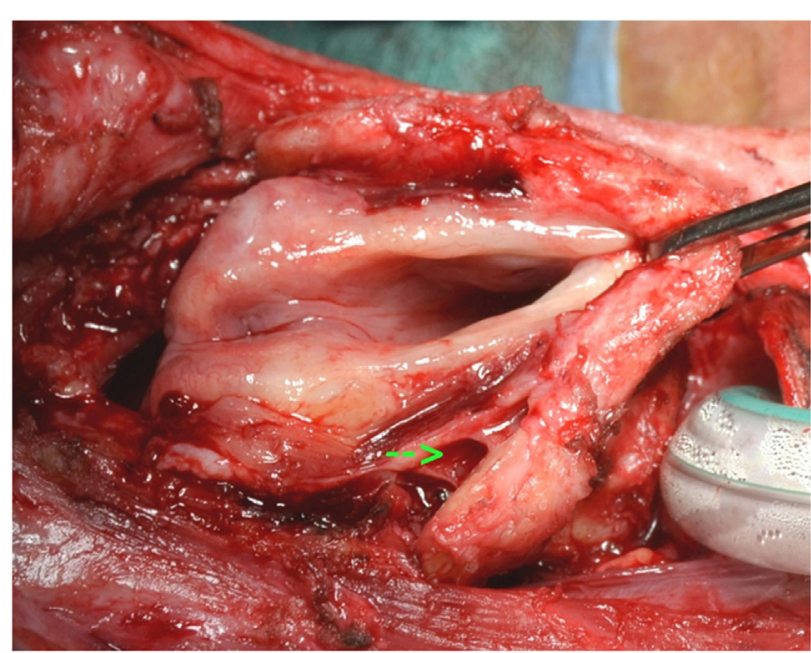

FIGURE 3 | Exposure of larynx in a case after horizontal laryngectomy. Note the freeing of the pyriform sinus on the right (arrow). 


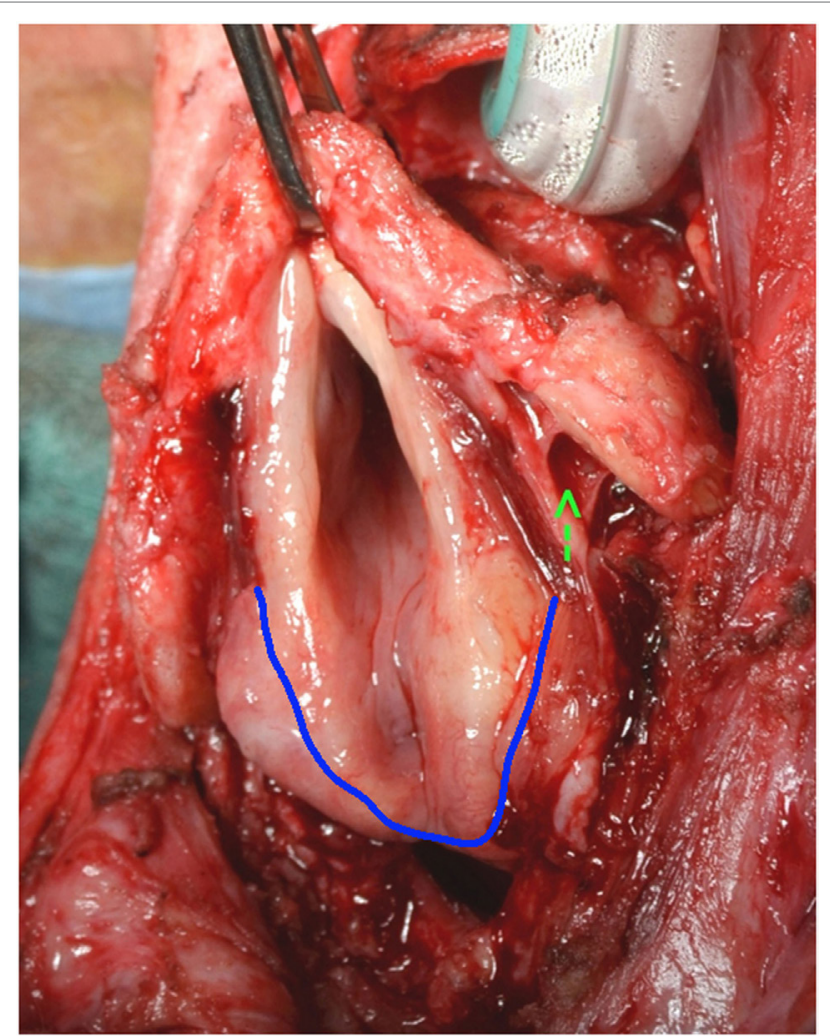

FIGURE 4 | Retroarytenoid incision (blue line).

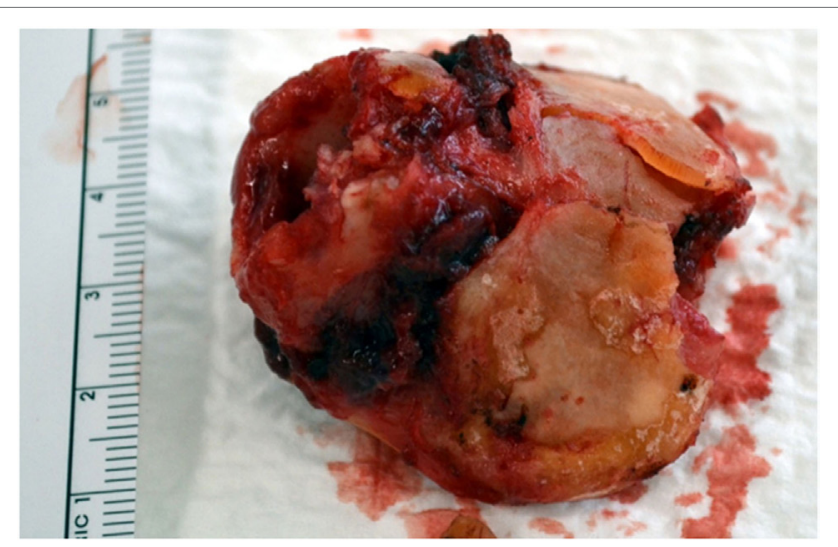

FIGURE 5 | Laryngectomy specimen, essentially made of laryngeal cartilages.

\section{Study Population}

We retrospectively analyzed all consecutive patients who underwent maximal mucosal-sparing total laryngectomy (MMSTL) between 2014 and 2016.

Demographic variables, previous treatments, and their complications, the reason for the functional laryngectomy, and possible complications were extracted from the patient's records and tabulated (Table 1).

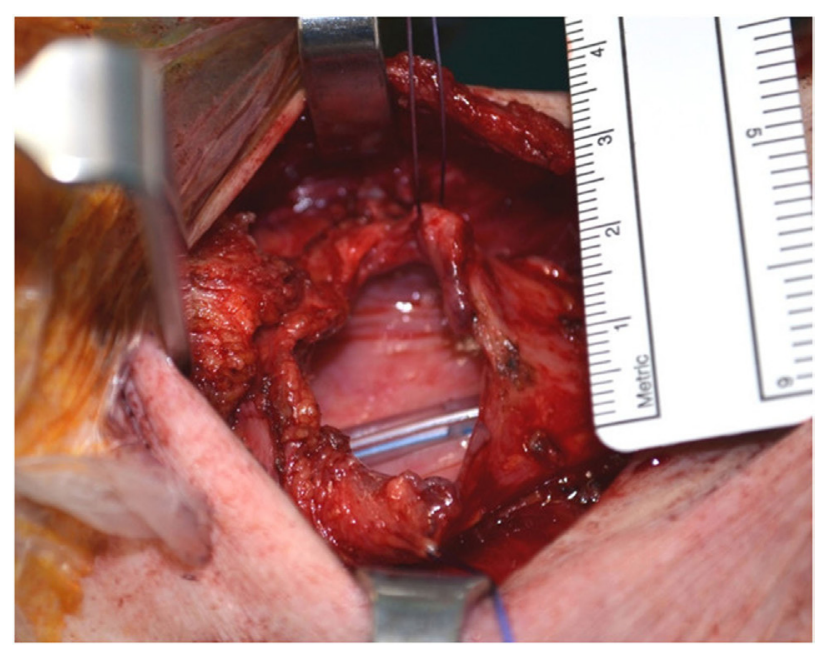

FIGURE 6 | Small pharyngeal opening, about $5 \mathrm{~cm}$ that will be closed horizontally.

\section{RESULTS}

Ten patients underwent MMSTL. Their average age was $71 \pm 9$ years. The average BMI was $18.7 \pm 8$. They all had a dysfunctional larynx and swallowing, with $90 \%$ already having a feeding tube and $50 \%$ having a tracheostomy in place.

The average duration of surgery was $121 \pm 32 \mathrm{~min}$. The average hospital stay was $20 \pm 4$ days for the entire cohort and $17 \pm 2$ days for the patients without fistula. All patients resumed oral diet and had their feeding tube removed.

Only one patient developed a postoperative fistula requiring a suprascapular pediculated fascio-cutaneous flap for closure.

\section{DISCUSSION}

Variables rates (3-66\%) of pharyngocutaneous fistula after total laryngectomy have been reported (2), the average being about $14.3 \%$ (95\% CI 11.7-17.0) (3). One meta-analysis concluded that postoperative hemoglobin level, prior tracheotomy, preoperative radiotherapy, and concurrent neck dissection were associated with increased fistula rates (2). Considering salvage total laryngectomy, the fistula rates vary between 14 and $61 \%$ (3), and a meta-analysis concluded to average fistula incidence of $27.6 \%$ (23.4-31.8) (3). Fistula rates after radiotherapy alone were $22.8 \%$ (18.3-27.4) and $34.1 \%(22.6-45.6)$ after chemoradiotherapy (3). Flap-reinforced closure decreased the fistula incidence to $10.3 \%(4.6-15.9)$ (3) and has become routine practice in the majority of centers.

Robotics-associated advantages aside, transoral total laryngectomy introduced the concept of mucosa sparing, which results in a minimal pharyngotomy defect and a horizontal closure, as well as minimal lateral dissection toward the neck and preservation of prelaryngeal muscles that in turn allow to minimize the risk of fistula. In the same year as the initial technical article, two cases of cancer-free dysfunctional larynx operated 
TABLE 1 | Patient characteristics.

\begin{tabular}{|c|c|c|c|c|c|c|c|c|c|c|}
\hline Age & Sex & $\begin{array}{c}\text { Year of } \\
\text { diagnosis }\end{array}$ & $\begin{array}{l}\text { Carcinoma } \\
\text { location }\end{array}$ & Stage & Carcinoma therapy & Comorbidities & Tracheostomy & $\begin{array}{l}\text { Feeding } \\
\text { tube }\end{array}$ & Reason for MMFTL & Fistula \\
\hline 81 & $\mathrm{M}$ & $\begin{array}{l}1997 \\
2008\end{array}$ & $\begin{array}{l}\text { Oral cavity } \\
\text { Larynx }\end{array}$ & $\begin{array}{l}\text { T4aN1 } \\
\text { T1aN0 }\end{array}$ & $\begin{array}{l}\text { Resection + RT } \\
\text { Laser cordectomy }\end{array}$ & Cachexia & No & Yes & Aspiration pneumonia & No \\
\hline 54 & $\mathrm{M}$ & $\begin{array}{l}2010 \\
2013\end{array}$ & $\begin{array}{l}\text { Oropharynx } \\
\text { Recurrence }\end{array}$ & $\mathrm{T} 2 \mathrm{~N} 1$ & $\begin{array}{l}\text { RT } \\
\text { Parotidectomy + radical } \\
\text { neck dissection + carotid } \\
\text { artery graft + ChemoRT }\end{array}$ & $X+X I I$ palsy & Yes & Yes & Aspiration pneumonia & No \\
\hline 69 & $\mathrm{M}$ & $\begin{array}{l}2009 \\
2014\end{array}$ & $\begin{array}{l}\text { Oropharynx } \\
\text { Supraglottis }\end{array}$ & $\begin{array}{l}\text { T2N2a } \\
\text { T3N0 }\end{array}$ & $\begin{array}{l}\text { Neck } \\
\text { dissection + ChemoRT } \\
\text { Supraglottic laryngectomy }\end{array}$ & Lung cancer & Yes & Yes & Aspiration pneumonia & No \\
\hline 66 & $\mathrm{M}$ & 1997 & Larynx & T2NO & ChemoRT & Stroke & Yes & Yes & Aspiration pneumonia & No \\
\hline 72 & $\mathrm{~F}$ & & $\begin{array}{l}\text { ALS with me } \\
\text { RT } 7.5\end{array}$ & $\begin{array}{l}\text { ajor swallov } \\
\text { Gy to saliva }\end{array}$ & $\begin{array}{l}\text { wing disability } \\
\text { ary glands }\end{array}$ & - & No & Yes & $\begin{array}{l}\text { Aspiration pneumonia } \\
\text { No speech + no oral feeding }\end{array}$ & No \\
\hline 70 & $\mathrm{~F}$ & $\begin{array}{l}2002 \\
2003\end{array}$ & $\begin{array}{l}\text { Oropharynx } \\
\text { Recurrence }\end{array}$ & $\mathrm{T} 4 \mathrm{aN} 2 \mathrm{~b}$ & $\begin{array}{l}\text { ChemoRT } \\
\text { Neck dissection + carotid } \\
\text { artery graft }\end{array}$ & $\begin{array}{l}\text { Bilateral cord } \\
\text { palsy } \\
\text { Cachexia }\end{array}$ & No & Yes & Aspiration pneumonia & No \\
\hline 78 & M & 2015 & Larynx & T3NO & ChemoRT & $\begin{array}{l}\text { Parkinson } \\
\text { Chondronecrosis }\end{array}$ & Yes & Yes & No speech + no oral feeding & Yes \\
\hline 81 & M & $\begin{array}{l}2009 \\
2014\end{array}$ & $\begin{array}{l}\text { Oropharynx } \\
\text { Oral cavity } \\
\text { Recurrence }\end{array}$ & $\begin{array}{l}\text { T2NO } \\
\text { T2NO }\end{array}$ & $\begin{array}{l}\text { ChemoRT } \\
\text { Transoral resection } \\
\text { Composite resection }\end{array}$ & - & No & Yes & $\begin{array}{l}\text { No oral } \\
\text { feeding + oropharyngeal } \\
\text { stenosis and invalidating } \\
\text { crusting }\end{array}$ & No \\
\hline 80 & $\mathrm{~F}$ & 1998 & Oropharynx & T1N2b & $\mathrm{RT}$ & Cachexia & No & No & $\begin{array}{l}\text { Recurrent pharyngeal and } \\
\text { supraglottic narrowing }\end{array}$ & No \\
\hline 59 & $\mathrm{~F}$ & 2015 & Larynx & T3N1 & CHEP + ChemoRT & - & Yes & Yes & Aspiration pneumonia & No \\
\hline
\end{tabular}

with a similar technique were published (4) as well as five cases, four of which had a recurrent carcinoma after chemoradiation (5). One of the cases described developed a postoperative fistula.

In our opinion, the surgical technique of open MMSTL outlined here retains all of the advantages of transoral robotic total laryngectomy: (1) minimal neck incisions; (2) maximal mucosa sparing; (3) minimal pharyngotomy defect; (4) minimal lateral dissection toward the carotid sheath; (5) horizontal closure; and (6) preservation of prelaryngeal muscles, allowing minimizing the risk of fistula.

We fail to grasp what advantages doing part of the surgery with an endoscopic exposure might accomplish. Having a slightly smaller (1-2 cm less?) neck incision and possibly a slightly smaller pharyngotomy defect is probably not of tremendous advantage. Furthermore, the amount of surgery done endoscopically vs. the amount of dissection through the neck opening is unclear in the published reports.

The major advantage of both approaches is to obliviate the need of flaps without increasing the rate of post-laryngectomy fistula. In the published literature, so far one of seven patients operated with transoral laryngectomy developed a fistula, an incidence comparable to our series, as well as to the cited $10 \%$ fistula rate after salvage total laryngectomy with flap coverage (3).

Other obvious advantages of open MMSTL are (1) quickness, with a procedure duration of about $2 \mathrm{~h}$; (2) lack of endoscopic exposure problems, the previous radiation, and/or surgery precluding sufficient neck extension in majority of the targeted population; (3) no need of special training since the procedure steps are familiar to head and neck surgeons; and (4) equipment related costs.

We have used MMSTL only for functional laryngectomy and not for oncologic total laryngectomy. It is probably possible to modify the technique in some cases of salvage or primary laryngectomy for cancer, when the disease bulk is limited and does extend either anteriorly through the thyroid or cricoid cartilages or posteriorly to the arytenoids and retrocricoid region.

\section{CONCLUSION}

Open maximal mucosal-sparing total laryngectomy without a flap is associated with low rates of postoperative fistula and seems to present several advantages to transoral robotic total laryngectomy.

\section{ETHICS STATEMENT}

Retrospective chart studies of patients are waived of formal approval by the hospital ethics committee.

\section{AUTHOR CONTRIBUTIONS}

All the authors: conception of the work, analysis, and interpretation of data; final approval of the version to be published; agreement to be accountable for all aspects of the work in ensuring that questions related to the accuracy or integrity of any part of the work are appropriately investigated and resolved. 


\section{REFERENCES}

1. Lawson G, Mendelsohn AH, Van Der Vorst S, Bachy V, Remacle M. Transoral robotic surgery total laryngectomy. Laryngoscope (2013) 123(1):193-6. doi:10.1002/lary.23287

2. Paydarfar JA, Birkmeyer NJ. Complications in head and neck surgery: a meta-analysis of postlaryngectomy pharyngocutaneous fistula. Arch Otolaryngol Head Neck Surg (2006) 132(1):67-72. doi:10.1001/archotol.132.1.67

3. Sayles M, Grant DG. Preventing pharyngo-cutaneous fistula in total laryngectomy: a systematic review and meta-analysis. Laryngoscope (2014) 124(5):1150-63. doi:10.1002/lary.24448

4. Dowthwaite S, Nichols AC, Yoo J, Smith RV, Dhaliwal S, Basmaji J, et al. Transoral robotic total laryngectomy: report of 3 cases. Head Neck (2013) 35(11):E338-42. doi:10.1002/hed.23226
5. Smith RV, Schiff BA, Sarta C, Hans S, Brasnu D. Transoral robotic total laryngectomy. Laryngoscope (2013) 123(3):678-82. doi:10.1002/lary.23842

Conflict of Interest Statement: The authors declare that the research was conducted in the absence of any commercial or financial relationships that could be construed as a potential conflict of interest.

Copyright (c) 2017 Dulguerov, Alotaibi, Lambert, Dulguerov and Becker. This is an open-access article distributed under the terms of the Creative Commons Attribution License (CC BY). The use, distribution or reproduction in other forums is permitted, provided the original author(s) or licensor are credited and that the original publication in this journal is cited, in accordance with accepted academic practice. No use, distribution or reproduction is permitted which does not comply with these terms. 